\title{
PLICAÇÃO DO MÉTODO PDCA PARA REDUÇÃO DO RISCO DE EXPLOSÃO NA OPERAÇÃO DE TRANSPORTE DE GRÃOS
}

Recebido: 11/03/2019

Aprovado: 08/06/2019
${ }^{1}$ Elaine Patussi da Silva

${ }^{2}$ Verica Marconi Freitas de Paula

${ }^{3}$ Verônica Angélica Freitas de Paula

\section{Resumo}

Este relato tecnológico descreve a experiência de um grupo de Melhoria Contínua (CCQ) de uma organização de transporte integrado para a redução de risco de explosão na planta operacional devido a alguns fatores como excesso de pó, poeira e baixa umidade. Com a aplicação do Método PDCA e de ferramentas de Qualidade, o grupo delineou duas propostas de ação. A proposta escolhida, de custo consideravelmente inferior, foi implementada - as metas estabelecidas foram superadas, proporcionando ainda melhorias em diferentes aspectos da operação da organização.

Palavras-chave: Método PDCA. CCQ. Melhoria Contínua. Transporte de grãos.

1Universidade Federal de Uberlândia - UFU, Minas Gerais, (Brasil). E-mail: elainepatussi6@gmail.com Orcid id: https://orcid.org/0000-0003-0647-4955

${ }_{2}$ Faculdade de Gestão e Negócios da Universidade Federal de Uberlândia - FAGEN/UFU, (Brasil). E-mail: verica@ terra.com.br Orcid id: https://orcid.org/0000-0003-3035-9738

${ }^{3}$ Faculdade de Gestão e Negócios da Universidade Federal de Uberlândia - FAGEN/UFU (Brasil). E-mail: veronica@ufu.br Orcid id: https://orcid.org/0000-0002-1560-614X 


\title{
APPLICATION OF PDCA METHOD TO REDUCE EXPLOSION HAZARD IN GRAIN TRANSPORT OPERATION
}

\begin{abstract}
This technological paper describes the experience of a Continuous Improvement Group (QCC) of an integrated transportation organization to reduce the risk of explosion at the operating plant due to factors such as dust excess and low humidity. With the application of the PDCA Method and Quality tools, the Group outlined two action proposals. The chosen proposal, the one with a more affordable cost, was implemented, surpassing the established goals and providing improvements in different aspects of the organization's operation.
\end{abstract}

Keywords: PDCA. Quality Control Circles (QCC). Continuous Improvement. Grains Transportation. 


\section{INTRODUÇÃOO}

Para distâncias superiores a $500 \mathrm{~km}$, a eficiência do transporte ferroviário é superior à do transporte rodoviário, com menor emissão de poluentes, implicando em custos sociais reduzidos (Villar \& Marchetti, 2207), proporcionando custo de frete e manutenção mais baixos (Vale, 2017). No Brasil, as ferrovias transportaram cerca de $15 \%$ da produção total de transporte em 2015 (EPL, 2018), movimentando quase 500 milhões de toneladas úteis (Ministério dos Transportes, 2015).

Tradicionalmente são transportados itens de valor agregado inferior pelas ferrovias, que teriam custos logísticos impeditivos se fosse utilizado o transporte rodoviário (Villar \& Marchetti, 2007). Granéis agrícolas, como soja, milho e farelo de soja, ocupam a $2^{a}$ posição no volume de carga ferroviária no Brasil (EPL, 2018).

Para empresas que trabalham com grãos é imprescindível a armazenagem em silos e armazéns. De acordo com dados do Instituto Brasileiro de Geografia e Estatística [IBGE] (2018), os silos para grãos apresentaram em média 43.701.611 toneladas de capacidade útil total do Brasil, detendo a região Sul $54,9 \%$ desse total e as regiões Centro-Oeste e Sudeste 26,5\% e 13,5\%, respectivamente.

O transporte de grãos em locais subterrâneos é realizado por esteiras para entrada/saída dos produtos, sendo que essas esteiras que se estendem até o local de armazenagem (armazém/silo), geram partículas de poeiras que são consideradas explosivas, por isso a necessidade de realizar análises em determinadas áreas de armazenamento (Sá, 2007).

Considerando silos e armazéns, os principais riscos para os trabalhadores são: explosões; problemas ergonômicos; lesões respiratórias (poeiras) e lesões oculares; riscos físicos (ruído, iluminação, umidade e vibrações); e acidentes gerais como queda e asfixia. As avaliações dos riscos referentes a poeiras consideram a quantificação das partículas de vários materiais e a medição realizada em laboratório avalia a quantidade de poeira presente no ar que pode levar a explosões.

Para reduzir o risco de explosão no processo da empresa Beta, foi aplicado o Método PDCA por uma equipe de Melhoria Contínua com intuito de auxiliar na melhoria dos processos ligados ao transporte de grãos em túneis subterrâneos.

O Ciclo PDCA é um método de melhoria utilizado para confrontar desafios, focado em gerenciar diretrizes, ou seja, é um sistema que auxilia na solução de problemas que são fundamentais para a organização (Aguiar, 2006).

Para que os resultados do Ciclo PDCA sejam mais consistentes e que a tomada de decisão seja adequada, são utilizadas algumas ferramentas da qualidade. Cada ferramenta da qualidade tem um objetivo e uma forma diferente para auxiliar nas análises e verificação dos resultados.

A empresa estudada oferece soluções logísticas integradas aos negócios de seus clientes e tem o compromisso de entregar valor para todos os envolvidos na cadeia de suprimentos, oferecendo um sistema integrado com ativos próprios e de terceiros, utilizando ferrovias, portos e terminais,

A organização está presente em alguns estados brasileiros, atuando em diversas frentes para garantir maior capilaridade e interiorização, alcançando regiões com alto potencial, operando com ferrovias e 
terminais intermodais que recebem as cargas de seus clientes e fazem escoamento ou abastecimento por meio de corredores logísticos. Sua estrutura é composta por armazéns, silos, sistemas de alta performance para carregamento e descarga ferroviária.

\section{REFERENCIAL TEÓRICO}

Para Khanna, Laroiya e Sharma (2010), a Gestão pela Qualidade é uma filosofia que une conceitos, métodos e aplicações, promovendo a transformação organizacional, gerando melhoria no desempenho de organizações manufatureiras e na competitividade da qualidade.

Organizações que querem melhorar o nível de qualidade de seus produtos e serviços, bem como aumentar a eficiência e a produtividade de seus processos utilizam a melhoria contínua, que objetiva continuadamente promover mudanças e melhorias organizações através de análises e estudos realizados em equipe, utilizando ferramentas e técnicas como o Método PDCA, o Diagrama de Ishikawa e o Plano de ação, dentre outros (Fonseca, Leite, Freitas, Vieira, \& Fujiyama, 2016). A melhoria contínua utiliza ferramentas mais simples para análise (Morais et al., 2015), sendo a sua aplicação acessível a qualquer funcionário.

Sokovic, Pavletic e Pipan (2010) destacam que o Método PDCA é utilizado por organizações que buscam melhorar seus resultados de maneira recorrente, fazendo parte da cultura organizacional, possibilitando ações tanto temporárias quanto permanentes: a primeiro visa eliminar reduzir o impacto do problema detectado; já as permanentes tratam de investigar e eliminar as causas-raiz, evitando que o resultado indesejado aconteça novamente.

O Ciclo PDCA é composto por quatro etapas que auxiliam os grupos de CCQ a analisarem determinado processo e conseguirem encontrar o problema, a causa do problema e a melhor solução para que ocorra a melhoria do processo. De acordo com Campos (2013), as etapas do ciclo PDCA possuem os seguintes significados:

- $1^{\text {a }}$ Etapa: Plan - essa etapa de planejamento consiste em definir a meta e encontrar meios e caminhos (plano de ação) para atingir determinada meta;

- $2^{a}$ Etapa: $D o$ - consiste em colocar em prática o plano de ação definido na etapa do planejamento e coletar as informações/dados para obtenção da meta;

- $\quad 3^{a}$ Etapa: Check - nessa etapa ocorre a verificação e análise dos dados e informações coletados na etapa de execução e relacionando com o alcance da meta; e

- $4^{a}$ Etapa: Action - a última etapa depende dos resultados alcançados nas etapas anteriores. Caso a meta seja alcançada, devem ser criados meios para manter os bons resultados, caso a meta não seja alcançada, o ciclo retorna novamente para a primeira etapa com intuito de atingir a meta estabelecida.

Nessa linha, alguns estudos demonstram o impacto da utilização do Método PDCA e/ou de algumas ferramentas da Qualidade para aumento da eficiência operacional: Baker, Tavares, Mothé e Morais (2014) demonstram que a análise de um processo produtivo na Companhia Siderúrgica Nacional (CSN) proporcionou redução drástica na frequência de interrupções no processo produtivo para limpeza, 
podendo impactar na produtividade da organização; Ferreira, Peruchi e Vieira (2017) demonstram o alcance da meta de zero reclamações em um frigorífico; e Realyvásquez-Vargas, Arredondo-Soto, Carrillo-Gutiérrez e Ravelo (2018) apresentam a a redução do desperdício em uma indústria manufatureira com a aplicação do Método PDCA associado com algumas ferramentas da Qualidade.

Outros estudos, como Quiarato, Lima e Fuzeto (2017) e Maiczuk e Andrade (2013) detalham a utilização de algumas das ferramentas da Qualidade para a melhoria de resultados organizacionais, em organizações de diferentes segmentos, destacando alguns resultados, como redução do desperdício e melhoria da produtividade organizacional.

Carpinetti (2012) lista as ferramentas básicas e as ferramentas gerenciais da Qualidade, dentre elas estão: Folha de verificação; Diagrama de Pareto; Diagrama de Causa e Efeito; Histograma; Diagrama de Dispersão; e Gráficos de Controle. Este relato tecnológico apresenta a aplicação do Método PDCA com a utilização de algumas ferramentas da Qualidade.

\section{Método de Produção Técnica}

O presente estudo é uma pesquisa qualitativa exploratória que, de acordo com Roesch (2007, p. 154), pode ser utilizada para "avaliação informativa, quando se trata de melhorar a efetividade de um programa ou plano, ou mesmo quando é caso da proposição de planos, ou seja, quando se trata de selecionar metas de um programa e construir uma intervenção".

Segundo Creswell (2014), a pesquisa qualitativa pode se basear em perspectivas construtivistas e/ou participativas, com o uso de estratégias como o estudo de casos, de forma que os pesquisadores coletem dados de forma ampla, e desenvolvendo ideias, análises e padrões a partir dos dados coletados. Para este relato tecnológico, os autores optaram por desenvolver pesquisa qualitativa, de cunho exploratório, visando conhecer o caso em estudo (Gil, 2010).

Em se tratando de pesquisa qualitativa, os autores optaram por utilizar a pesquisa-ação como estratégia de pesquisa para descrever o caso. De acordo com Thiollent (1986), a pesquisa-ação é um tipo de pesquisa que possui base empírica, realizado em associação com a resolução de um problema em que algum pesquisador e participantes representativos do problema estão envolvidos de modo cooperativo ou participativo. Assim, a pesquisa-ação foi escolhida por enfatizar procedimentos adequados à solução de problemas práticos (Creswell, 2012).

A partir de dados primários, obtidos através de participação ativa e observação direta, e de dados secundários obtidos em estudos, relatórios e sites da organização estudada e outras instituições relacionadas, os autores desenvolveram este relato buscando apresentar o caso, descrevendo suas etapas e servindo como referência de melhores práticas.

Este relato tecnológico segue a estrutura proposta por Biancolino, Kniess, Maccari e Rabechini (2012) e traz a descrição da experiência de um grupo de melhoria contínua para a redução de risco de explosão na planta operacional decorrente de fatores como excesso de pó, poeira e baixa umidade. $\mathrm{O}$ grupo de melhoria contínua (CCQ), atuante em uma organização de transporte integrado, aplicou o 
Método PDCA e ferramentas de qualidade para delinear duas propostas de ação; e a proposta escolhida, com custo inferior, foi implementada com sucesso pela organização.

Assim, este relato apresenta a descrição da organização e do problema enfrentado; referencial teórico de suporte ao caso; as etapas desenvolvidas pelo grupo de melhoria contínua (CCQ) para solução do problema, seguindo o método PDCA; e considerações finais com a análise do caso. Visando preservar a identificação dos envolvidos, foi utilizado o nome fictício Beta para descrever a organização estudada.

\section{APLICAÇÃo PRÁtICA}

\section{Etapa Planejamento (Plan) - Identificação do Problema}

O grupo de CCQ iniciou o estudo a partir de um Branstorming - nesse caso, o importante era expor o máximo de gargalos dos processos operacionais da empresa, sendo: Mau aproveitamento de espaço do armazém nas células 1 e 5; Alto risco de explosão; Constante entupimento das bicas do armazém; Falta de visibilidade da quantidade de produto na tulha; Excesso de produto em cima de vagão; e Elevado tempo de setup.

Após identificarem os principais problemas, eles forem classificados através da Matriz GUT, onde cada problema é classificado por três fatores: gravidade, urgência e tendência. Os problemas ficaram classificados de acordo com a Figura 1.

\begin{tabular}{|c|c|c|c|c|}
\hline Problema & Gravidade & Urgência & Tendência & Total \\
\hline $\begin{array}{c}\text { Mal aproveitamento do espaço do armazém nas células } \\
1 \text { e 5 }\end{array}$ & 3 & 3 & 3 & 9 \\
\hline Alto risco explosão & 9 & 9 & 9 & 27 \\
\hline Constante entupimento das bicas do armazém. & 3 & 3 & 1 & 7 \\
\hline Excesso de produto em cima de vagão & 9 & 3 & 3 & 15 \\
\hline Alto tempo de setup & 3 & 3 & 3 & 9 \\
\hline Falta de visibilidade da quantidade de produto na tulha & 9 & 3 & 3 & 15 \\
\hline
\end{tabular}

Figura 1: Matriz GUT

Analisando a pontuação, é possível observar que o problema de ALTO RISCO DE EXPLOSÃO obteve 27 pontos, com a maior da classificação. Portanto, foi o problema definido para análise, sendo esperado que, ao final do Ciclo PDCA, houvesse uma possível alternativa para minimizar/eliminar o risco de explosão dentro dos processos operacionais da empresa.

\section{Contextualização do problema}

A empresa estudada possui como seus principais produtos a soja e o milho que durante o processo de armazenagem e expedição soltam uma poeira que pode ser considerada altamente explosiva de acordo com Sá (2007). Para esclarecer o motivo dessa poeira ser explosiva é necessário contextualizar sobre a Teoria do Fogo. De acordo com Ferrari (2016), o fogo possui quatro elementos: Combustível; Comburente; Calor; e Reação em cadeia. 
Para que surja fogo, é necessário existir um combustível que, atingindo seus pontos de fulgor e combustão, gera gases inflamáveis, que misturados com um comburente (geralmente oxigênio contido no ar), precisam apenas de uma fonte de calor (Faísca elétrica, chama ou superaquecimento), para inflamar e começar a reação em cadeia. Nos processos operacionais da Beta, há todos os quatro elementos referente a teoria do fogo: Combustível $=$ Poeira em Suspensão; Comburente $=$ Oxigênio; Calor = Faísca, Fumo e Solda; e Reação em cadeia = junção dos três primeiros elementos gerando o fogo/explosão.

Na Figura 2, é possível analisar o número de desvios relatados por trabalhadores operacionais devido ao excesso de poeira, sendo que de 2015 para 2016 houve $57 \%$ de aumento.

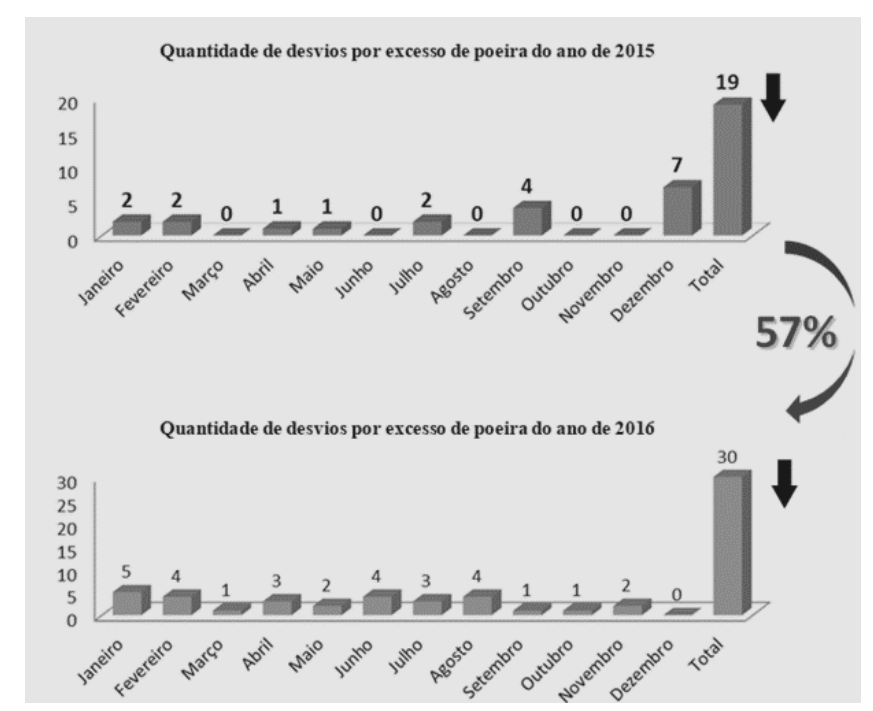

Figura 2: Históricos de desvios

Outro fator que pode aumentar o risco de explosão é a umidade, que está diretamente relacionada a poeira estar no ponto para que a reação em cadeia ocorra; a umidade abaixo de $50 \%$ é caracterizada como faixa crítica de risco de explosão (Sá, 2007). Para analisar a umidade na Beta, alguns pontos operacionais foram escolhidos aleatoriamente e identificados como: TRG01; TRG02; TRG04; e EL. A partir dessa identificação, foram coletadas as informações e analisando os números, o percentual de umidade ficou abaixo de $50 \%$ em todos os pontos selecionados conforme a Figura 3, indicando uma criticidade referente à umidade. Para os pontos TGR01, TRG02 e TRG04, a umidade real do ambiente operacional estava cerca de $18 \%$ abaixo da umidade necessária para que não houvesse riscos de explosões.

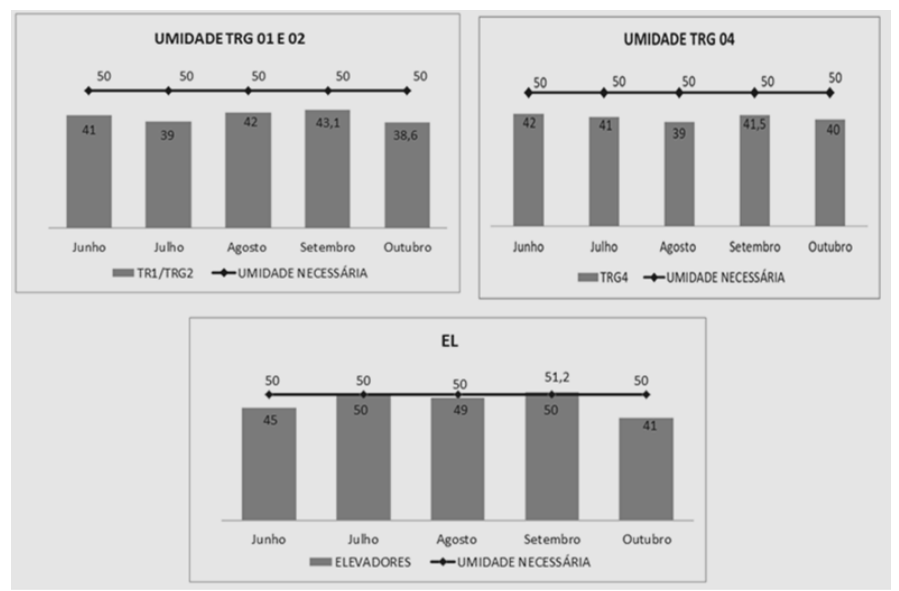

Figura 3: Umidade ambiente 


\section{Definição da Meta}

A partir de todas as informações obtidas na identificação do problema, foi evidenciado um alto risco de explosão nas atividades operacionais da empresa estudada e que para minimizar ou eliminar esse risco é necessário retirar um dos quatro elementos da Teoria do Fogo.

Analisando os elementos do fogo, é possível verificar que o comburente e calor não podem ser mitigados, pois um é o elemento mais abundante da terra e o outro está ligado as atividades operacionais da empresa. Com isso, para não ocorrer o quarto elemento - Reação em cadeia, é necessário minimizar o combustível - poeira em suspensão. Como não é possível ficar sem poeira nas atividades operacionais devido aos processos da empresa, o grupo decidiu minimizar o risco de explosão aumentando a umidade relativa do ar. Assim, o objetivo deste estudo foi aumentar a umidade ambiente em $25 \%$ reduzindo o risco de explosão pelo pó em suspensão nos pontos selecionados.

\section{Análise do Fenômeno}

Para conseguir entender melhor o problema, o grupo utilizou a ferramenta 5W2H com finalidade de obter o máximo de clareza e eficiência sobre o problema identificado.

1. Qual é o problema?

> Alto risco de explosão ocasionado pelo excesso de pó (poeira) em suspensão;

2. Onde ocorre o problema?

$>$ Em qualquer terminal durante a operação de carregar e descarregar o produto;

3. Como ocorre o problema?

$>$ Ocorre durante o transporte do produto pelas correias transportadoras.

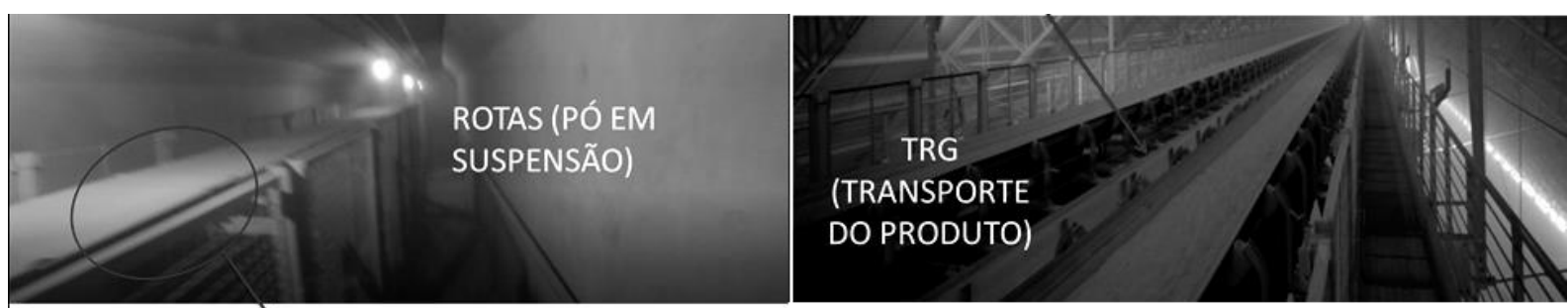

Figura 4: Transporte de produto por correias transportadoras

4. Com quem ocorre o problema?

$>$ Com todos que estão envolvidos diretamente com o processo: manutenção; operadores de rotas; auxiliares de limpeza; e visitantes.
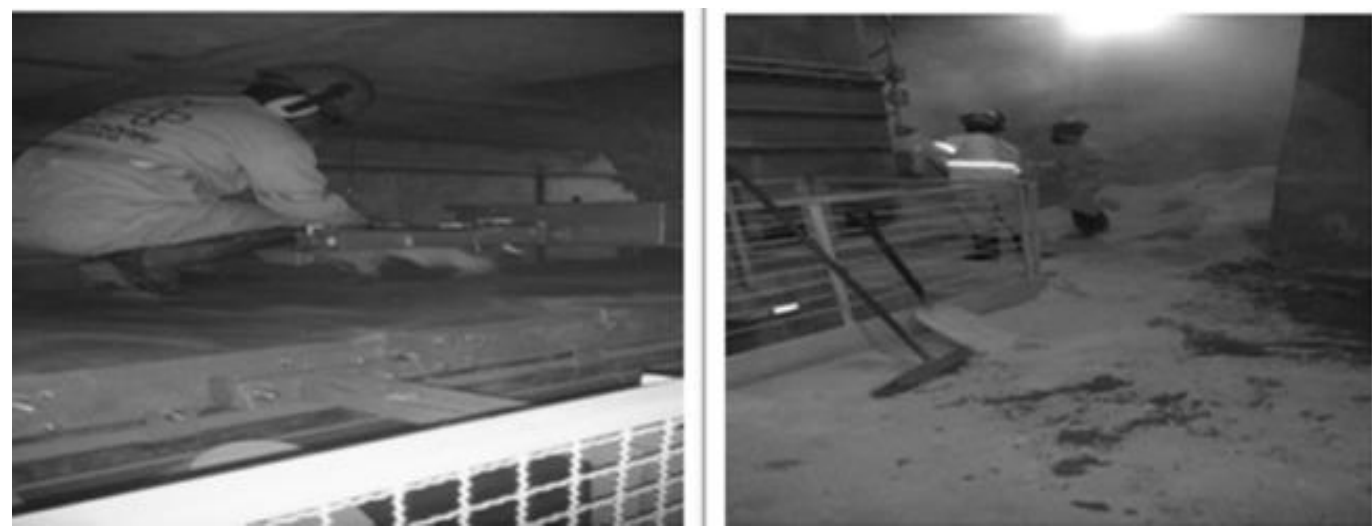

Figura 5: Funcionários em atividade

Revista Inovação, Projetos e Tecnologias. São Paulo | v.7 | n.2 | p. 202-215 | Jul/Dez 2019. 
5. Com que frequência ocorre o problema?

$>$ Tempo integral de funcionamento do processo de carga e descarga dos produtos;

6. Por que ocorre o problema?

$>$ Ineficiência do Sistema de Despoeiramento; Excesso de Pó em Suspensão; Ausência do controle da umidade ambiente;

Com todos os esclarecimentos acima, é possível notar que a situação atual do ambiente operacional da empresa Beta está com a umidade do ambiente abaixo de $50 \%$ e alta concentração de pó em suspensão. Com isso, reafirma-se a necessidade de manter a umidade ambiente nos pontos selecionados acima de $50 \%$.

\section{Análise do Processo}

Analisando o problema através do Diagrama de Árvore, foram identificadas três causas primárias indicadas na Figura 6. A primeira causa relacionada foi a BAIXA UMIDADE, onde detectaram que todos os locais selecionados estavam com a umidade ambiente variando entre mínima de $18 \%$ e máxima de $50 \%$. A segunda causa foi a alta temperatura nos ambientes operacionais, que está ligada diretamente com a umidade. Portanto, estabilizando a umidade, a temperatura também ficaria estável.

A terceira causa foi a alta concentração de pó (poeira) em suspensão devido às atividades operacionais da empresa estudada. Porém, a alta poeira também está relacionada à umidade ambiente, pois de acordo com Sá (2007), as micropartículas em um ambiente com a umidade acima de 50\%, se aglomeram e ficam mais estáveis, minimizando/eliminando o risco de explosão pelo pó em suspensão.

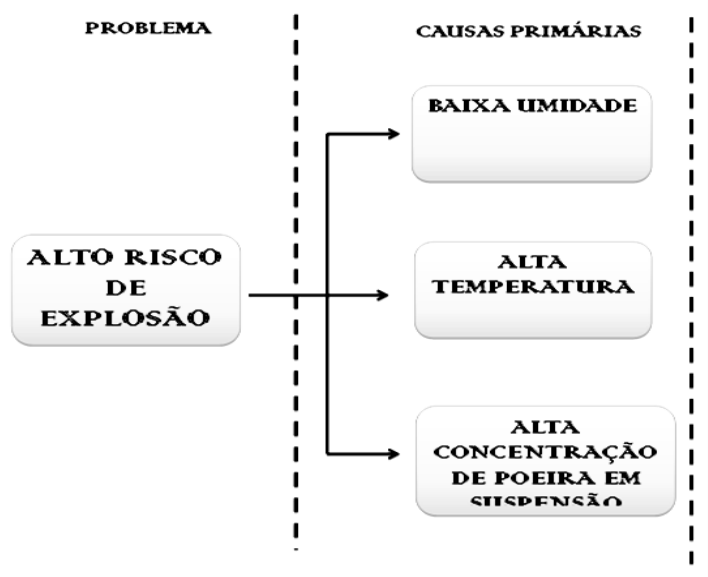

Figura 6: Diagrama de Árvore

\section{Análise de Viabilidade - Plano de ação}

O grupo de CCQ apresentou duas propostas para a liderança, com intuito de uma delas ser aprovada. A primeira proposta era realizar um investimento para instalar um sistema de despoeiramento adequado para a estrutura da empresa, mas devido ao seu alto custo, no valor aproximadamente de R \$ 1 milhão, a proposta foi reprovada.

A segunda proposta foi desenvolver um sistema a base de água, que melhorasse a umidade nos pontos selecionados minimizando o pó em suspensão, com o valor do investimento de aproximadamente R \$ 70 mil. 
Essa aprovada foi a aprovada, pois a liderança da organização acredita que é possível fazer mais com menos e com simplicidade. Dessa forma, o grupo apresentou o plano de ação (Figura 7), para desenvolver a proposta aprovada - esse plano de ação continha atividades para todos os integrantes do grupo de CCQ, assim todos participariam com ótimo desenvolvimento e compromisso.

\begin{tabular}{|c|c|c|c|c|c|c|c|c|}
\hline & $1^{\circ}$ Ação & $Z^{\circ}$ Açajo & $3^{\circ}$ Açajo & $4^{\circ}$ Aç̧āo & $5^{\circ}$ Açāo & $6^{\circ}$ Açajo & $7^{\circ}$ Af̧ảo & $8^{\circ}$ Açäo \\
\hline Medida & $\begin{array}{c}\text { Verificar umidade } \\
\text { nas rotas }\end{array}$ & $\begin{array}{l}\text { Verificar a existēncia } \\
\text { do sistema de } \\
\text { aspersão no } \\
\text { iransporte de grãos }\end{array}$ & $\begin{array}{l}\text { Fazer levantamento } \\
\text { de empresas que } \\
\text { desenvolveramo } \\
\text { sistema de aspersão }\end{array}$ & $\begin{array}{l}\text { Verificar local da } \\
\text { instalação do } \\
\text { sıstema de } \\
\text { aspersão. }\end{array}$ & $\begin{array}{l}\text { Bustar orçamento } \\
\text { com as empresas. }\end{array}$ & $\begin{array}{c}\text { Solicitar prototipo } \\
\text { para a empresa } \\
\text { escolhida }\end{array}$ & $\begin{array}{c}\text { verificar se afetara } \\
\text { a qualidade do } \\
\text { produto. }\end{array}$ & $\begin{array}{l}\text { acompanhar a } \\
\text { instalação do } \\
\text { sistema de } \\
\text { aspersão. }\end{array}$ \\
\hline Oque? & $\begin{array}{c}\text { Levaniamento de } \\
\text { dados }\end{array}$ & $\begin{array}{c}\text { Levantamento de } \\
\text { dados }\end{array}$ & $\begin{array}{c}\text { Levantamento de } \\
\text { dados }\end{array}$ & $\begin{array}{c}\text { verificar instalaçòes } \\
\text { do termınal }\end{array}$ & $\begin{array}{c}\text { Levantamento de } \\
\text { dados }\end{array}$ & $\begin{array}{l}\text { Levantamento de } \\
\text { dados }\end{array}$ & $\begin{array}{c}\text { Levantamento de } \\
\text { Dados }\end{array}$ & Instalaçăo in loco \\
\hline Como? & $\begin{array}{l}\text { Comauxilio do } \\
\text { Termohigrómetro } \\
\text { digital }\end{array}$ & $\begin{array}{c}\text { Realizar pesquisa na } \\
\text { Internet e fazer } \\
\text { benchmarking }\end{array}$ & Realizar pesquisa & $\begin{array}{c}\text { Visita tecnica das } \\
\text { empresas na } \\
\text { localıdade }\end{array}$ & $\begin{array}{c}\text { Empresa que } \\
\text { realizou visita } \\
\text { técnica }\end{array}$ & $\begin{array}{c}\text { Instalação de um } \\
\text { prototipo para } \\
\text { realizar testes de }\end{array}$ & $\begin{array}{l}\text { Coletar umidade do } \\
\text { grão semanalmente }\end{array}$ & $\begin{array}{l}\text { Instalar o sistema } \\
\text { de aspersão nas } \\
\text { àreas escolnidas }\end{array}$ \\
\hline Quew? & & & 1 & & & & & i \\
\hline Quando? & Maio/2016 & Junho/2016 & Agosto/2016 & Setembro/2016 & Setembro/2016 & Outubro/2016 & Novembro/2016 & Novembro/2016 \\
\hline
\end{tabular}

Figura 7: Plano de Ação

\section{Etapa da Execução (Do)}

Todas as ações foram realizadas para a implantação da proposta aprovada, conforme demonstra a Figura 8.

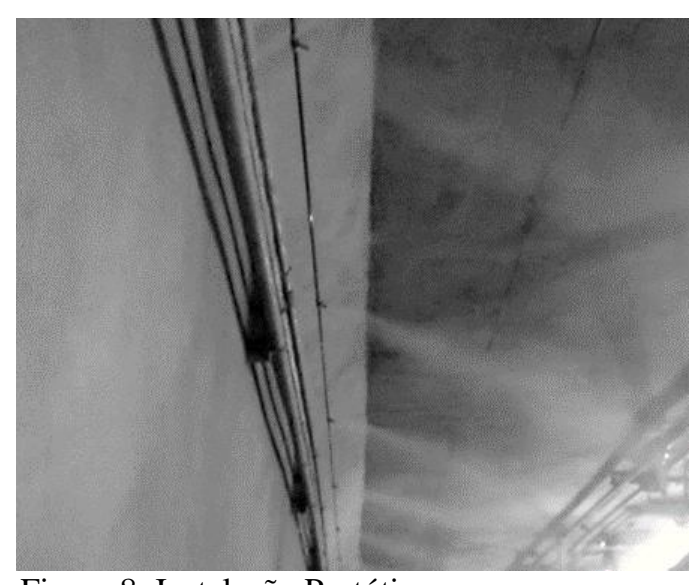

Figura 8: Instalação Protótipo

Para verificar a qualidade do produto, funcionários responsáveis pela área da qualidade e perdas da empresa realizaram o diagnóstico coletando as amostras a partir da instalação do protótipo. O diagnóstico foi positivo, onde o sistema de aspersão de água não modificou o produto, mantendo suas características fisiológicas, não alterando a umidade do grão.

O sistema de aspersão de água foi instalado nos pontos selecionados aleatoriamente para análise. O diferencial é o sistema via supervisório onde é factível controlar e verificar a temperatura e a umidade ambiente em tempo real. O sistema possui um acionamento automático ou manual, sendo possível inserir uma umidade mínimo-máxima nos locais de instalação. Assim, o sistema poderia ligar e desligar 
automaticamente sem necessitar de pessoal para atividade. Após instalação, foi elaborado um plano de manutenção para o sistema para que ele continuasse a funcionar adequadamente (Figura 9).
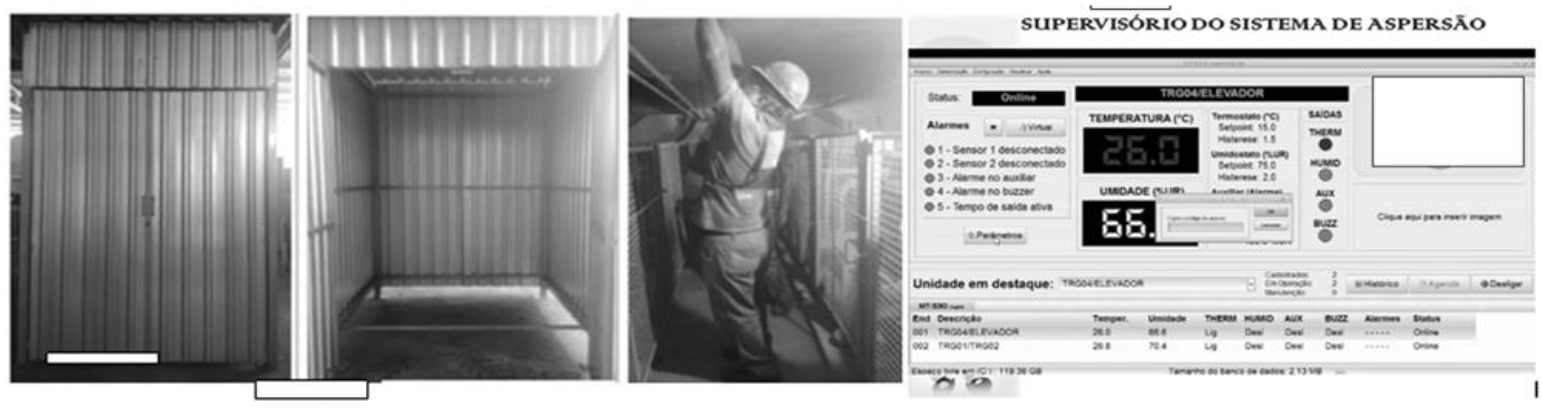

Figura 9: Instalação Sistema

\section{Etapa da Verificação (Check)}

Com sistema de aspersão de água instalado conforme Figura 10, foi iniciada a coleta de dados para análise e verificação da umidade. Foi possível notar que o ambiente ficou mais arejado após a instalação, melhorando também o ambiente de trabalho para os funcionários. Através do sistema via supervisório, gráficos que indicam o nível de umidade durante determinado período podem ser obtidos (Figura 11).

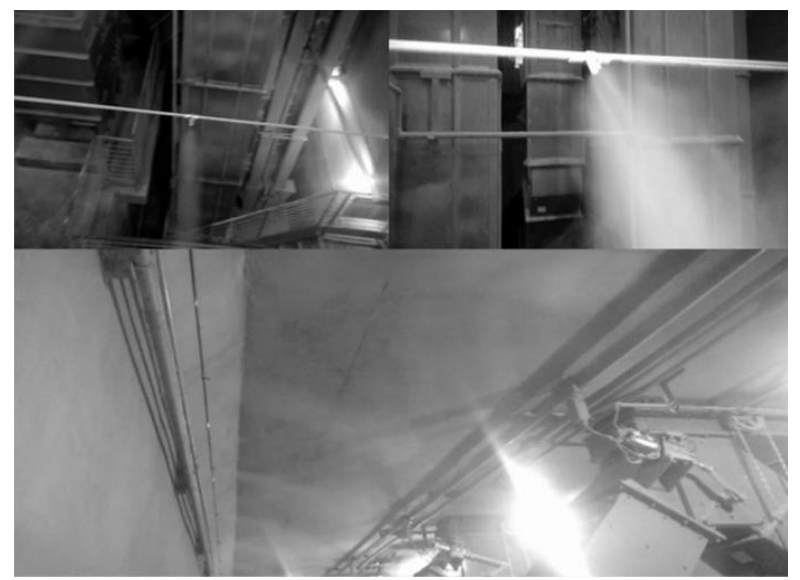

Figura 10: Sistema Instalado
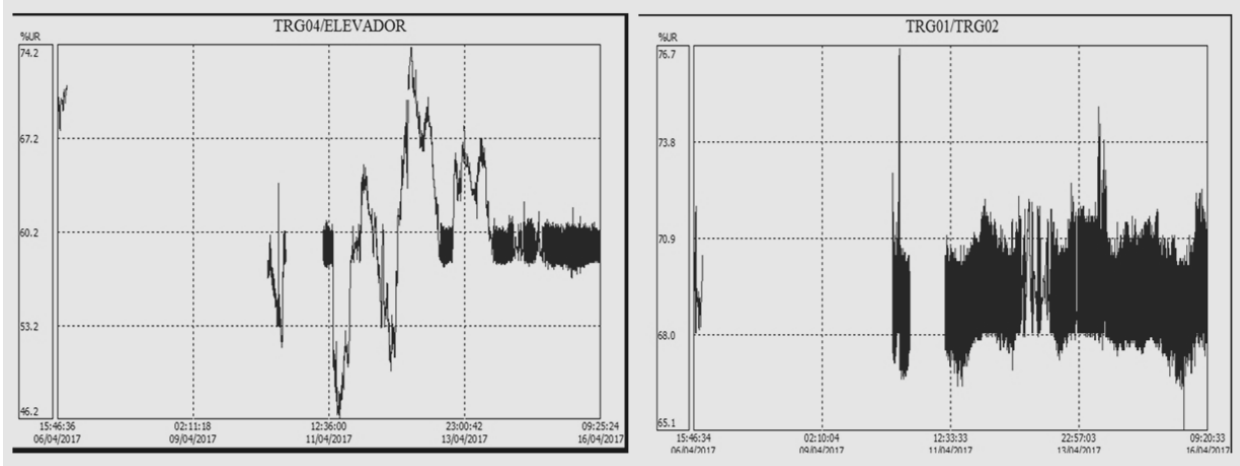

Figura 11: Gráficos de umidade Sistema Supervisório

Após a instalação do sistema, houve melhoras significativas quanto ao aumento da umidade nos locais de instalação, conseguindo nos pontos da TRG01, TRG02 e TRG04 aumentar a umidade em até $73,5 \%$, obtendo uma média de umidade de $70 \%$ nesses locais. Para o local de instalação EL, a partir da 
instalação do sistema a umidade aumentou em 48,5\%, chegando também em 70\%, conforme Figura 12. Portanto, o objetivo do trabalho delineado pela equipe de melhoria contínua foi atingido com sucesso, superando a proposta apresentada de aumentar a umidade em $25 \%$.

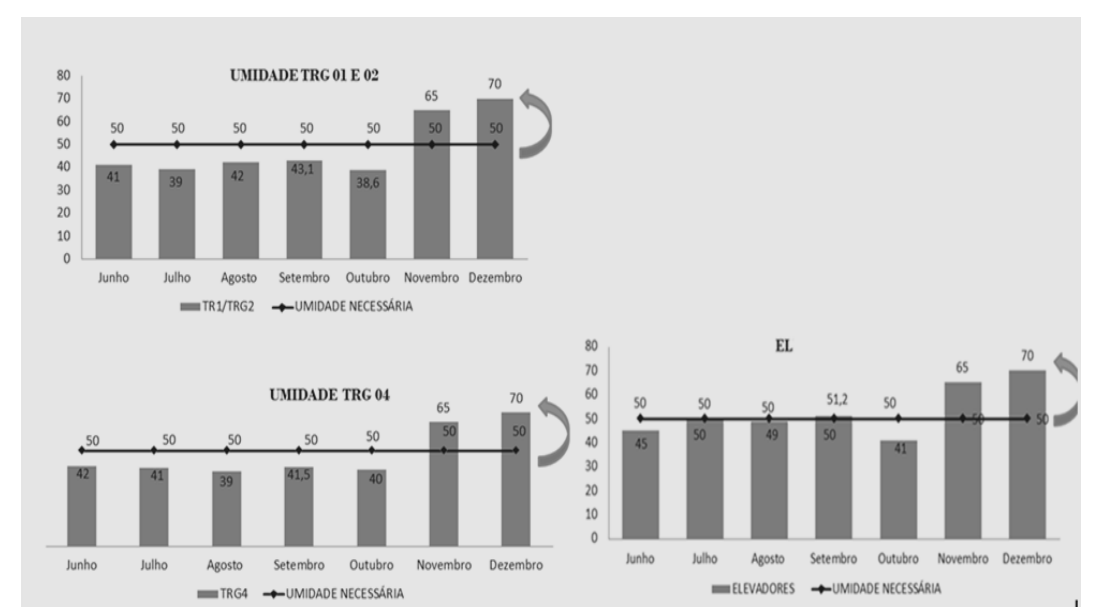

Figura 12: Gráficos de umidade Antes/Depois

\section{Etapa Agir (Action)}

Todo o trabalho foi divulgado nas redes de comunicação da empresa, recebendo o auxílio técnico dos inspetores para elaborar o documento padrão e treinar todos os funcionários envolvidos no novo processo definido a partir dos levantamentos, estudos e melhorias realizados.

\section{CONSIDERAÇÕES FINAIS}

Este trabalho permitiu avaliar que o Método PDCA pode contribuir para melhorias de processos e resultados operacionais, sendo que a sua aplicação aliada a algumas ferramentas da qualidade possibilita conhecer e entender o problema ou o resultado indesejado, permitindo aperfeiçoar os processos, reduzir custos e alcançar as metas definidas pela organização.

Outro ponto importante é que o trabalho foi desenvolvido e aplicado por funcionários das áreas operacionais e administrativas da organização, ficando evidente que o Método utilizado na prática através da pesquisa de campo e o comprometimento de todos, pode, além de trazer os ganhos e as melhorias almejados, colabora para aumento da vivência e da experiência de cada funcionário envolvido.

É interessante comentar ainda que a participação e o envolvimento dos funcionários que atuam diretamente no processo em estudo são essenciais, pois eles conhecem a situação real da operação, colaborando de maneira ímpar na identificação de possíveis causas e na proposição de ações.

Dessa forma, este trabalho elucida o caso de alcance de um importante resultado operacional para a organização em estudo, trazendo benefícios financeiros, de redução do risco e de desconforto aos funcionários. Assim, como demonstrado em estudos prévios e na teoria, há evidências da possibilidade de utilização do Método PDCA associado a ferramentas da Qualidade para promover a melhoria contínua nas organizações. 
É interessante destacar que o caso estudado trata especialmente de operações realizadas no transporte ferroviário, que possui papel de destaque no Brasil, notadamente para a movimentação de commodities, sendo que o critério de desempenho custo é fator distintivo do transporte ferroviário brasileiro e primordial para produtos de baixo valor agregado, como as commodities. Dessa forma, é essencial que os resultados indesejados e as não-conformidade sejam analisados e tratados através de ferramentas de gestão para promover a eficiência operacional, contribuindo com a sustentabilidade do negócio.

Para estudos futuros, é interessante analisar as principais ferramentas da Qualidade utilizadas pelas Equipes de Melhoria Contínua para realização das análises propostas nas etapas do Método PDCA, visando identificar a motivação pela escolha de determinada ferramenta, bem como os benefícios percebidos por quem a utiliza.

\section{REFERÊNCIAS}

Aguiar, S. (2006). Integração das Ferramentas da Qualidade ao PDCA e ao Programa Seis Sigma. Nova Lima, MG: Editora INDG.

Baker, J. A., Tavares, R. J., Mothé, V. M. \& Morais, L. M. de. (2014). Análise do rejeito de sacos de cimento na CSN Cimentos em Volta Redonda/RJ. Cadernos UniFOA (Edição Especial Engenharia de Produção), 9(1), 29-43.

Biancolino, C. A., Kniess, C. T., Maccari, E. A., \& Rabechini, R., Jr. (2012). Protocolo para elaboração de relatos de produção técnica. Revista de Gestão e Projetos, 3(2), 294-307.

Campos, V. F. (2013). TQC: Controle da Qualidade Total (no estilo japonês) (9a ed.). Nova Lima, MG: Editora Falconi. Atlas.

Carpinetti, L. C. R. (2012). Gestão da Qualidade: conceitos e técnicas. (2a ed.). São Paulo, SP: Editora

Creswell, J. W. (2014). Research Design: qualitative, quantitative, and mixed methods approaches (4th ed.). Los Angeles, California: Sage Publications.

Creswell, J. W. (2012). Educational Research: planning, conducting and evaluating quantitative and qualitative research (4th ed). Boston, Massachusetts: Pearson.

EPL. (2018). Plano Nacional de Logística PNL - 2025 (relatório executivo). Recuperado em 12 de dezembro, 2019, de https://www.epl.gov.br/plano-nacional-de-logistica-pnl

Ferrari, B., Jr. (2016). Curso de Formação de Brigadistas [Apostila de treinamento do Corpo de Bombeiros do Espírito Santo]. Governo do Espírito Santo, Secretaria da Segurança Pública e Defesa Nacional, Corpo de Bombeiros Militar. Recuperado em 29 de julho, 2019, de https://cb.es.gov.br/Media/CBMES/PDF's/CEIB/SCE/Material\%20Didatico/CFBP\%20\%20PREVEN\%C3\%87\%C3\%830\%20E\%20COMBATE\%20A\%20INC\%C3\%8ANDIOS\%20-\%202016.pdf

Ferreira, I. S. B., Peruchi, R. S. \& Vieira, R. de M. (2017). Análise e aplicação da metodologia PDCA para melhoria no processo de produção de sobrecoxa de peru: estudo de caso em um abatedouro de aves. In: Simpósio de Engenharia de Produção (SIENPRO), 194-201, Catalão, Goiás.

Fonseca, C. M. da, Leite, J. C., Freitas, C. A. de O., Vieira A. da S. \& Fujiyama, R. S. (2016). Proposal for improvement the welding process of the micro- USB connector on the mother board on tablets. Journal of Engineering and Technology for Industrial Applications (JETIA), 2(6), 39-47. 
Gil, A. C. (2010). Como elaborar projetos de pesquisa (5a ed). São Paulo, SP: Atlas.

Instituto Brasileiro de Geografia e Estatística (2018). Capacidade de armazenagem agrícola fica em 167 milhões de toneladas no $2^{\circ}$ semestre de 2017 - 2018. Recuperado em 22 de setembro, 2018, de https://agenciadenoticias.ibge.gov.br/agencia-sala-de-imprensa/2013-agencia-de-noticias/releases/21405capacidade-de-armazenagem-agricola-fica-em-167-milhoes-de-toneladas-no-2-semestre-de-2017

Khanna H. K., Laroiyaa, S. C. \& Sharmaa, D. D. (2010). Quality Management in Indian Manufacturing Organizations: Some Observations and Results from a Pilot Survey. Brazilian Journal of Operations \& Production Management, 7 (1), 141-162.

Maiczuk, J. \& Andrade, P. P., Jr. (2013). Aplicação de ferramentas de melhoria de qualidade e produtividade nos processos produtivos: um estudo de caso. Qualit@s Revista Eletrônica, 14 (1), 1-14.

Ministério dos Transportes. (2015). Transportes 2015. Recuperado em 12 de dezembro, 2019, de https://www.infraestrutura.gov.br/images/2016/04/Transportes2015Versao Web.pdf

Morais, M. O., Brejão, A. S., Costa, P. L. O., Neto, Raymundo, H., Reis, J. G. M. dos, Vendrametto, O. ... Silva, H. R. O. (2015). Knowledge and Quality for Continuous Improvement of Production Processes. In: Anais do International Federation for Information Processing, 194-201, Hamburgo, Alemanha.

Quiarato, M. A., Lima, A. C. de \& Fuzeto, A. P. (2017). Implantação do sistema de gestão PDCA em instituição beneficente. Revista Fafibe On-Line, 10 (1), 204-222.

Realyvásquez-Vargas, A., Arredondo-Soto, K., Carrillo-Gutiérrez, T. \& Ravelo, G. (2018). Applying the plan-do-check-act (PDCA) cycle to reduce the defects in the manufacturing industry: a case study. Applied Sciences, 8(2181), 1-17.

Roesch, S. M. A. (2007). Projetos de estágio e pesquisa em administração: guia para estágios, trabalhos de conclusão, dissertações e estudos de caso (3a ed.). São Paulo, SP: Atlas.

Sá, A. (2007). Efeito Devastador. Revista Proteção, 181, 63-63. Recuperado em 06 de setembro, 2018, de http://www.ufrrj.br/institutos/it/de/acidentes/silo.htm

Sokovic, M., Pavletic, D. \& Pipan, K. K. (2010). Quality Improvement Methodologies - PDCA Cycle, RADAR Matrix, DMAIC and DFSS. Journal of Achievements in Materials and Manufacturing Engineering, 43(1), 476-483.

Thiollent, M. (1986) Metodologia da pesquisa-ação (2a ed.). São Paulo, SP: Cortez.

Vale. (2017). Qual a importância das ferrovias para o desenvolvimento socioeconômico? Recuperado em 12 de dezembro, 2019, de http://www.vale.com/brasil/PT/aboutvale/news/Paginas/qual-a-importanciadas-ferrovias-para-o-desenvolvimento-socioeconomico-de-um-pais.aspx

Villar, L. B; \& Marchetti, D. dos S. (2007). Dimensionamento do Potencial de Investimentos do Setor Ferroviário. Publicação do Banco Nacional do Desenvolvimento (BNDES). Recuperado em 12 de dezembro, $2019, \quad$ de https://web.bndes.gov.br/bib/jspui/bitstream/1408/14176/2/8\%20Dimensionamento\%20do\%20Potencial\%2 0de\%20Investimentos\%20do\%20Setor\%20Ferrovi\%C3\%A1rio_P_BD.pdf 